\title{
Aseptic Arthritis of the Bilateral Temporomandibular Joint Mimicking Rheumatological Diseases
}

\author{
Şerif Şamil KAHRAMAN, ${ }^{1}$ Gül İLHAN, ${ }^{2}$ Hanifi BAYAROĞULLARI, ${ }^{3}$ Mesut TUZLALI ${ }^{4}$ \\ ${ }^{1}$ Department of Otorhinolaryngology, Medical Faculty of Mustafa Kemal University, Hatay, Turkey \\ ${ }^{2}$ Department of Haematology, Medical Faculty of Mustafa Kemal University, Hatay, Turkey \\ ${ }^{3}$ Department of Radiology, Medical Faculty of Mustafa Kemal University, Hatay, Turkey \\ ${ }^{4}$ Department of Dentistry, Medical Faculty of Mustafa Kemal University, Hatay, Turkey
}

A 24-year-old male patient was admitted to the Otorhinolaryngology Department with complaints of pain for three days in the bilateral preauricular region. The pain was constant, severe, and increased when he reclined, chewed or talked. There was no medical history of fever or trauma. Physical examination findings included mild edema, allodynia, and hyperalgesia in the bilateral preauricular area and bilateral masseter muscle. Panoramic radiograph showed limited interincisal mouth opening $(12 \mathrm{~mm})$ (Figure 1a). A written informed consent was obtained from the patient.

Initial laboratory tests showed serum C-reactive protein of $154 \mathrm{mg} / \mathrm{L}(0-5)$, ferritin of $1314 \mathrm{ng} / \mathrm{mL}$ (15-200), leukocyte count of $22.1 \times 10^{3} / \mu \mathrm{L}$ (4-10), hemoglobin of $10.1 \mathrm{~g} / \mathrm{dL}$ (10-17), and total bilirubin of $2.31 \mathrm{mg} / \mathrm{dL}(0-1.1)$. The test for rheumatoid factor was negative. Significant inflammatory processes were seen on magnetic resonance imaging in $T_{2}$ (Figure 1b) and necrotic areas in the right ramus of the mandible were also seen as a hypointense signal in $\mathrm{T}_{2}$ (Figure 1c). Arthritis in the bilateral condylar head secondary to a sickle cell crisis was diagnosed after the analysis of the laboratory tests and images.
The patient was admitted to the hematology ward and received standard analgesia recommended for the treatment of severe pain consisting of nonsteroidal antiinflammatory
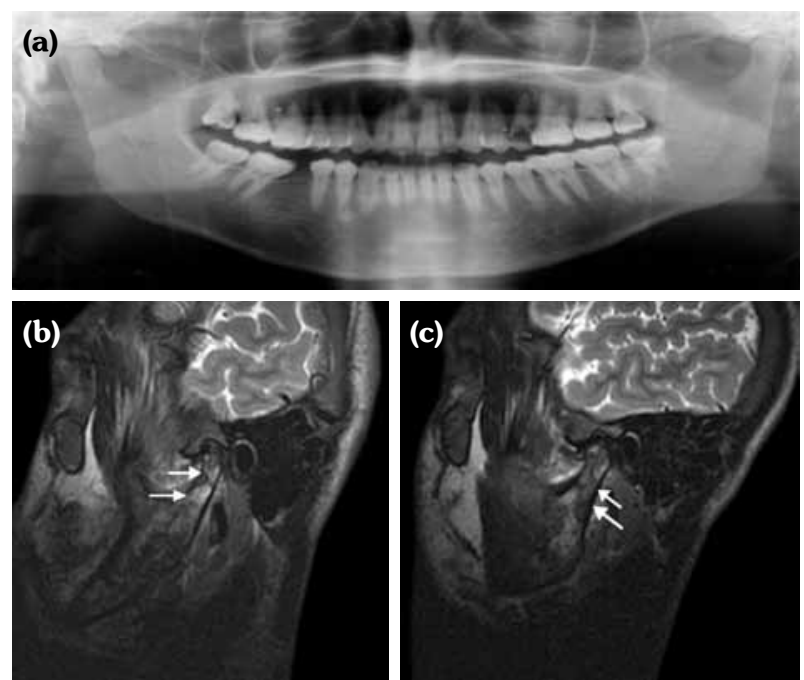

Figure 1. Panoramic radiograph imaging (a), magnetic resonance imaging of left temporomandibular joint showing a signal change at condylar head and neck of bilateral jaw, suggesting bone edema with $\mathrm{T}_{2}$ hypersensitivity (b) magnetic resonance imaging of right temporomandibular joint showing bilateral ramus infarction as a hypointense signal in $\mathrm{T}_{2}$ (c), (arrows). 
drugs and parenteral opioid analgesia. The pain gradually subsided after four days of hospital stay, allowing progressive weaning from the analgesic treatment. Mouth opening amplitude improved substantially to $40 \mathrm{~mm}$ at six months.

Almost half of sickle cell patients experience orofacial pain. ${ }^{1}$ Limb joint pain is common, but temporomandibular joint (TMJ) pain is rare. ${ }^{2}$ Clinicians should be aware that aseptic arthritis may occasionally be caused by sickle cell disease. ${ }^{3}$ The differential diagnosis should include avascular necrosis of the condylar head, manifestation of rheumatoid arthritis and juvenile rheumatoid arthritis in the TMJ, trauma and lupus arthritis of the TMJ. ${ }^{4}$

Laboratory tests and diagnostic imaging remain important for proper assessment due to the similarity of clinical manifestations of TMJ arthritis. Sickle cell disease may cause TMJ arthritis, and should be considered although rarely seen in the differential diagnosis of $\mathrm{TMJ}$ arthritis.

\section{Declaration of conflicting interests}

The authors declared no conflicts of interest with respect to the authorship and/or publication of this article.

\section{Funding}

The authors received no financial support for the research and/or authorship of this article.

\section{REFERENCES}

1. O'Rourke CA, Hawley GM. Sickle cell disorder and orofacial pain in Jamaican patients. Br Dent $J$ 1998;185:90-2.

2. Sansevere JJ, Milles M. Management of the oral and maxillofacial surgery patient with sickle cell disease and related hemoglobinopathies. J Oral Maxillofac Surg 1993;51:912-6.

3. Demirbaş AK, Ergün S, Güneri P, Aktener BO, Boyacioğlu $\mathrm{H}$. Mandibular bone changes in sickle cell anemia: fractal analysis. Oral Surg Oral Med Oral Pathol Oral Radiol Endod 2008;106:e41-8.

4. Fernandes EG, Savioli C, Siqueira JT, Silva CA. Oral health and the masticatory system in juvenile systemic lupus erythematosus. Lupus 2007;16:713-9. 